\title{
JUAN CARLOS MESTRE, EL POETA ENTRE DOS LENGUAS
}

\section{MARIO RODRÍGUEZ FERNÁN DEZ ${ }^{1}$}

A CASA ROJA2 2 , este hermoso y necesario libro de Juan Carlos Mestre, lo confirma como uno de los poetas ineludibles de la España actual.

Percibo en el texto dos líneas claras. Una de continuación, en la que Mestre tensa al máximo ese uso metafórico, simbólico, arquetípico y semicabalístico del lenguaje que caracteriza mayoritariamente sus libros anteriores, y otra de ruptura en que ejerce una desterritorialización de esa lengua extremada, oponiéndole una expresión material intensiva en que el significante se torna eminentemente sobrio.

Esta segunda lengua se hace más nítida a partir del epígrafe tomado de Hölderlin que apunta a "todos los lenguajes de la vida", en cuya persecución Mestre se vuelve nómada e inmigrante de su propia lengua. Para ello, comienza por arrancarle el sentido a las palabras, desplazándolo a un espacio de gran variabilidad, donde los significados pasan a depender de cada uno de nosotros, hasta transformarse en una pura intensidad, donde la palabra vale por "el como suena" y por el afecto que produce:

Para alguien que ha tenido un perro la palabra perro es fiel como la palabra amigo hermosa como la palabra estrella, necesaria como la palabra martillo

\footnotetext{
${ }^{1}$ Profesor de Literatura Chilena y Latinoamericana, Depto. de Español, Facultad de Humanidades y Arte, Universidad de Concepción. Concepción, Chile: E-mail: mariorod@udec.cl

${ }^{2}$ Madrid: Editorial Calambur, 2008, ISBN 9788483590355.
} 
El afecto e intensidad se realiza con una gran sobriedad lingüística y con el sigilo propio de un gitano, que ya no roba al niño alemán de su cuna, como propone Kafka, sino a la criatura metafórica que acompañaba la lengua poética de Mestre, depositando en la cuna semivacía, donde todavía quedan huellas simbólicas, algunas gotas de esa lengua cotidiana que, a partir de Nicanor Parra, define a la poesía chilena.

Propongo en este punto, que la estadía de Mestre y la frecuentación de los poetas pos parrianos en Chile introdujo variantes en su dicción poética.

Percibo a un poeta entre dos lenguas, ambas menores, en las que la minoridad se alcanza doblemente:

a) Enriqueciendo la lengua peninsular con todos los recursos del simbolismo y un trabajo de orfebre con el significante. Es el caso de sus primeros textos: La visita de Safo (1983) y Antífona del otoño en el valle del Bierzo (1985).

b) Oponiendo lo que Deleuze llama "un uso permanente intensivo de la lengua" a cualquier uso simbólico, como corresponde al texto que comento.

El primer modo de desterritorialización de la lengua desataba el peligro de llevar a Mestre a un callejón sin salida, apartándolo de ese pueblo (inventado) que el poeta ha necesitado siempre. Habría una posible salida política, nunca explícita, más bien larvada (presente en sus antepasados judíos) que con toda precaución podríamos llamar sionismo. La poderosa inclinación de Mestre por el pueblo no podía satisfacerse con esa salida sionista. Así lo demostraban poemas como "El niño John", en el que la enunciación se vuelve histórica, política y social:

El niño John no es el niño Juan

Los ojos del niño John y los ojos del niño Juan no ven las mismas cosas en el fondo del lago.

No por azar el texto figura nuevamente en esta parte de La Casa Roja. El poema es de una fuerza desterritorializante asombrosa. Un mínimo enunciado - "El niño John no es el niño Juan"- arrastra todos los dispositivos de enunciación que siguen. Enunciación y política se hacen una sola arrastrando imperialismos, clases sociales e ideologías. Mestre con una economía admirable - un adverbio de negación y dos nombres- ha logrado un efecto revolucionario sobre la lengua. Revolucionario en el sentido que ha abierto 
líneas de resistencia y desterritorializaciones de contenido y expresión imprevistos.

Ha encontrado un modo de expresión en el que la comunidad se reconoce cuando debe hablar. "El niño John no es el niño Juan" es una frase disponible para ser utilizada cuando alguien debe dirigirse al pueblo o cuando se necesita para expresar una verdad política o afirmar un juicio ético. No es que Mestre hable por el pueblo, eso sería incluso inmoral, sino que el poeta de Villafranca del Bierzo ha puesto la lengua a disposición del pueblo. Sólo los grandes poetas son capaces de hacerlo. Subrayo grandes porque he querido decir menores, pero corría el riesgo de producir la turbación de un equívoco. Poeta menor es aquel que revoluciona la estructura anquilosada de la lengua del poeta mayor.

Esa lengua mayor, políticamente conservadora, estéticamente inmutable, éticamente hipócrita, es la que minoriza Mestre.

Para desterritorializar la lengua usa un recurso que me sorprende y maravilla: la ironía, la risa. De ellas está lleno el texto. Poemas como "Alocución en la Academia de los botones chapados", "Pequeña conferencia", "Póliza", "Lince Ibérico", "Las espinas de la mandrágora", etc., acogen la ironía y aun lo cómico como actitudes relevantes. Ejemplifico con algunos versos: "no hay que ser gerente de una compañía eléctrica para oscurecer más las cosas" / "Adiós para siempre a las becas, good bye a los lectorados" / "Acabada la guerra fría comenzó la guerra ardiente" / "La ignorancia es lo último que se pierde" / "Un poema no es una misa cantada" / "Si calentamos el agua se nos derrama la leche" / "Insisto, no es bueno tener placeres violentos con uno mismo" / "Mi vecina está hecha a prueba de tontos" / "Chico quita chica a chico" / "Chica quita chico a chica" / "Tengo miedo a los aviones stop iré por tierra en un barquito de papel stop los mares están que arden stop tengan preparado el micrófono".

Tal como en "El niño Juan", donde hay una micropolítica capaz de transformarse en macro en cuanto el poema está al servicio de todos, hay en los versos citados una microironía, una microrrisa que puede arrasar con toda la realidad y hacerla explotar. ¿Qué hay detrás de ellas? Creo que un deseo de vida, deseo de libertad, de permitir que sus flujos recorran libremente el lenguaje, desquiciando los dispositivos del poder que pretenden encauzarlo en la trascendencia de la ley y del sujeto.

En esta relación con el deseo Mestre es muy sagaz. Como tal sabe que el deseo no puede estar directamente en escena porque empieza y termina oponiéndose a la ley, cuya trascendencia quiere dejar atrás.

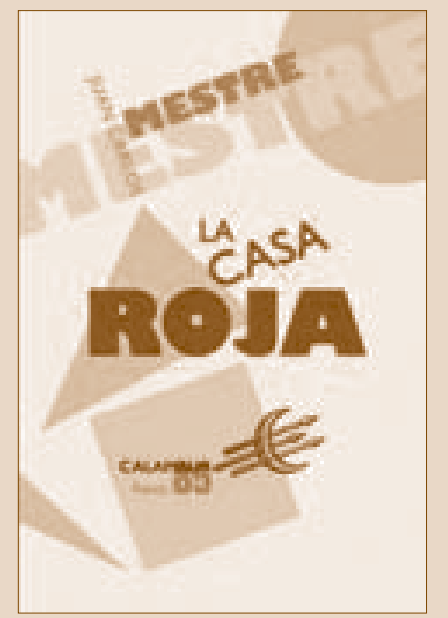


Por ello el sujeto deseante -de vida, solidaridad y amor- se oculta tras diversas máscaras. Las más frecuentes son las del orador, del tribuno, aun del predicador: "Queridos compañeros carpinteros y ebanistas" / "sastres y compatriotas" / "Señoras y señores” / "Señor Fiscal del Distrito" / "Por Júpiter, camaradas" / "Hermanos os aseguro que el evangelio predicado por mí".

En otros poemas, como "El mensajero de los astros", asume definitivamente el nombre de una figura canónica: "Y sin embargo yo, Galileo Galilei", que contrasta con la máscara de un poeta menor, como en el texto "El pasaporte de Orfeo": "Buenas noches, noche. Me llamó Moisés. Moisés Filadelfio Gutiérrez Gutiérrez, un poco más conocido como Rosamel del Valle”.

Predomina un tono festivo, hermanable, algo así como que quien habla está simultáneamente muerto de risa y de ternura por el otro.

Es el caso de los últimos versos citados, donde el nombre bíblico Moisés contrasta cómicamente con el de Filadelfio, que para más remate se apellida Gutiérrez Gutiérrez.

Este juego de máscaras, ironía y ternura cómica relativiza totalmente la presencia del yo en los poemas que aparentemente hablan desde la primera persona. Así en el texto "A la memoria de Joseph", ¿quién es este yo que se encuentra con Brodsky: "Tomé café con Brodsky en un bar del Gianicolo?". ¿O el que cena con Apollinaire? ¿Será posible que sea "San Sebastián picoteado por las gallinas"?

En resumen, Mestre habla desde las bambalinas. Por eso lo principal no sucede en el escenario, sino en lo que lo rodea fundamentalmente: los epígrafes que van en un abanico tan amplio como el territorio literario que media entre José Miguel Ullán (el primero de los epígrafes) y Henri Michaux (el último). Deben considerarse, también, las dedicatorias a familiares, a amigos, a poetas de todos los lares, etc., que permiten que el deseo circule secreto entre todos los mencionados. Así, uno de los poemas más deseantes, "La casa roja", que da el título al libro, está dedicado a Alexandra Domínguez, la esposa.

La alegría del deseo entre bambalinas junto al carácter político de la enunciación constituyen una "línea de fuga", una desterritorialización, que afecta a la lengua construida sobre el símbolo y la sacralización de la imagen, predominante, como propuse, en los libros anteriores de Mestre.

No significa, aclaro, que esta última lengua haya desaparecido, sino que es asediada, ahora, por una lengua poética instalada en la sobriedad. La casa roja, al debatirse entre dos lenguas, se instala en un "entre", se desliza, mejor, hacia ese "entre" (definido teóricamente por Deleuze) empujada por la "micropolítica" y el "microdeseo". 
De aquí nacen dos posibilidades de "interpretación”, quiero decir “experimentación", con el texto de Mestre.

La primera, la más usual, trascendental, metafísica, seria, semitrágica, que tendría puestos los ojos en lo que sucede sólo en el escenario y que transformaría todos los asuntos del texto en un problema individual.

La segunda forma, enfocada por el contrario en las bambalinas, sería capaz de descubrir tanto el carácter colectivo de la enunciación, por ende su naturaleza siempre política, como la fuerza jubilosa del deseo que inyecta humor, ironía y comicidad en el juego con el lenguaje.

Esta es la forma que he tratado de privilegiar, impulsado tal vez por el rechazo a la idea de que el poeta de genio siempre está unido a la angustia, a lo trágico y a su corolario el intimismo.

En este sentido, el título del trabajo podría haber sido perfectamente una cita de los versos ya citados: "Chico quita chica a chico" o "Chica quita chico a chica”. En ellos está el humor, el juego, la inversión irónica, que representan perfectamente la línea de juego vital, alegre, llena de risa que he creído ver en una parte de La casa roja.

Últimos puntos aclaratorios: la línea de fuga no aparece desde la nada. Estuvo siempre larvada en la poesía de Mestre. La experiencia chilena la fortaleció. Aunque reconozco que todo puede ser una engañifa: Mestre, stop acepta gustoso esta interpretación stop rectifico experimentación stop engañifa.

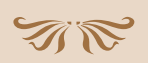

